
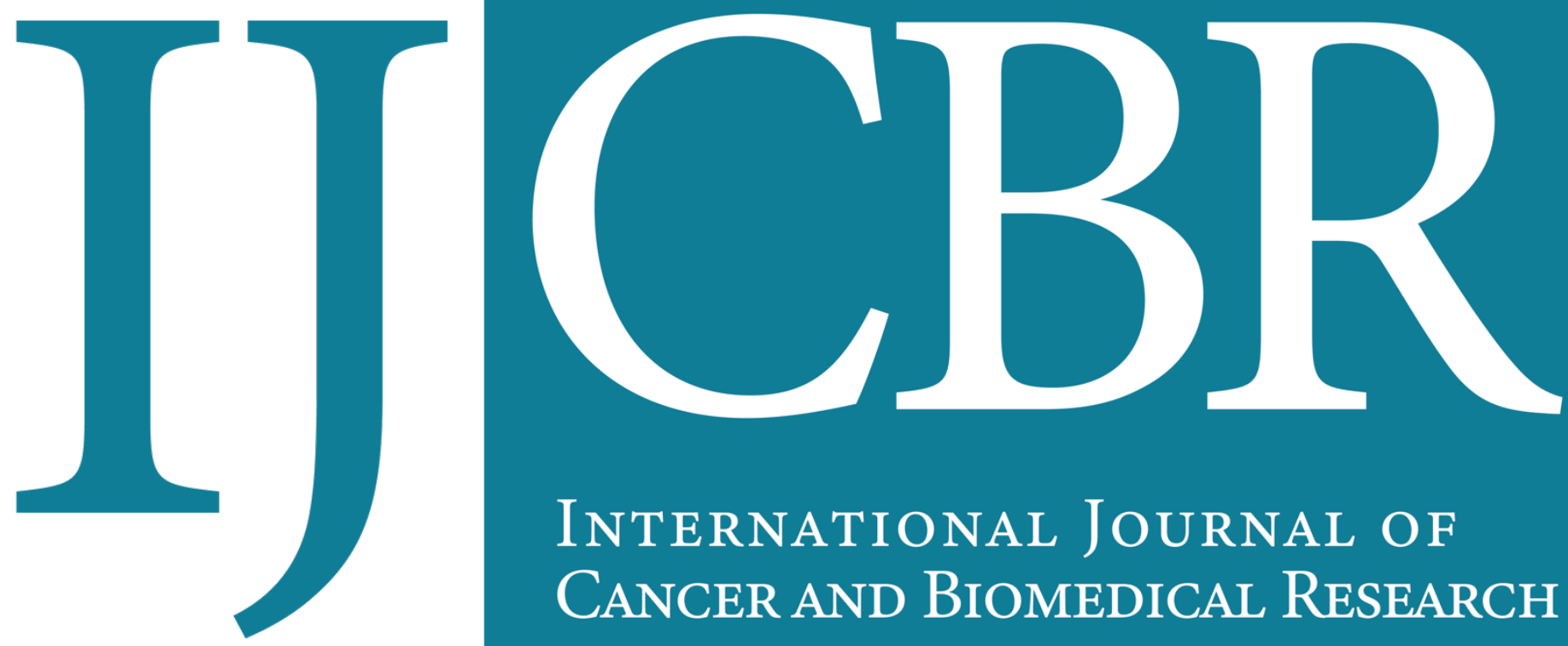

\title{
INTERNATIONAL JOURNAL OF CANCER AND BIOMEDICAL RESEARCH
}

https://jcbr.journals.ekb.eg

Editor-in-chief

Prof. Mohamed Labib Salem, PhD

Frequency of ALK gene rearrangement and its association with survival rate among Upper Egypt Non-Small cell lung cancer patients

Marwa I. Abdelgawad, Heba M. Saad Eldien, Ebtesam Elgezawy, Ahmed RH Ahmed ${ }^{4}$, Ahmed Badran, Marwa Y Nofal ${ }^{6}$, Sahar El Gammal, Khalid A Nasif and Eman Mosaad 


\title{
Frequency of ALK gene rearrangement and its association with survival rate among Upper Egypt Non-Small cell lung cancer patients
}

\author{
Marwa I. Abdelgawad ${ }^{1}$, Heba M. Saad Eldien², Ebtesam Elgezawy ${ }^{1,3}$, Ahmed RH Ahmed $^{4}$, Ahmed Badran $^{5}$, \\ Marwa Y Nofal ${ }^{6}$, Sahar El Gammal ${ }^{1}$, Khalid A Nasif ${ }^{7,8}$ and Eman Mosaad ${ }^{9}$ \\ ${ }^{1}$ Clinical Oncology Department, Faculty of Medicine, Assiut University, Egypt \\ 2 Histology and Cell Biology Department, College of Medicine, Jouf University, Saudi Arabia \\ 3 Prince Faisal Bin Khalid Cardiac Center, Abha, Saudi Arabia \\ ${ }^{4}$ Pathology Department, Faculty of Medicine, Sohag University, Egypt \\ ${ }^{5}$ Clinical Oncology Department, Faculty of Medicine, Ain Shams University, Egypt \\ ${ }^{6}$ Zoology Department, Faculty of Women for Arts, Science and Education, Ain Shams University. \\ ${ }^{7}$ Clinical biochemistry Department, College of Medicine, King Khaled University, Abha, Saudi Arabia \\ ${ }^{8}$ Medical Biochemistry Department, Faculty of Medicine, Minia University, Minia, Egypt \\ ${ }^{9}$ Clinical Pathology Department, South Egypt Cancer Institute, Assiut University, Egypt
}

III

$$
\text { ABSTRACT }
$$

Background: Anaplastic Lymphoma Kinase(ALK)gene rearrangement shows ethnic variations worldwide. There isn't a population-based study measuring its prevalence among the Egyptian population till now. Aim: To measure ALK gene rearrangement prevalence correlated with survival rates among a sample of Upper Egypt Non-Small Cell Lung Cancer (NSCLC) patients. Patients and Methods: The study included twentysix NSCLC patients. 21 of them were males and the rest were females, the enrolled patients had a median age of 60 years. 8 presented with pleural effusion, while 4 showed brain metastases, and 10 had liver metastases. Most of the cases were given a diagnosis with adenocarcinoma, squamous cell carcinoma (14, 6 cases, respectively), and the rest were given a diagnosis with undifferentiated carcinoma. Fluorescence Insitu Hybridization (FISH) technique was used for detection of rearranged ALK gene from FFEP Tissue Sections. Vysis ALK Break Apart FISH Probe Kit was used, it's composed of two probes green-labeled one to bind to the $5^{\prime}$ end of the ALK gene, and another orange labeled one to bind to the $3^{\prime}$ end. Tumor cells with $15 \%$ or more separate green $5^{\prime}$ and red $3^{\prime}$ signals or isolated red $3^{\prime}$ signals were considered positive for the rearranged ALK gene, while cells with yellowish signals (representing overlapped signals between green and red probes) were considered negative for ALK gene rearrangement. A fluorescence microscope supplied with a Leica CCD camera was used to detect clinicopathological characteristics of rearranged ALK gene, image processing was done using an imaging system and software. Results: Patients were followed up for 63 months, 15 of them were positive for the rearranged ALK gene. All patients were treated with chemotherapy and they had different objective response rates (ORR), ALK+ve cohort 73.3\% (PR:3, SD:8), ALK-ve cohort 100\% (PR:6, SD:5). The overall survival rate (OSR) was $51,6 \%$, and two- year progression-free survival rate (PFSR) was 68,8\%. Univariate analysis was done between ALK+ve / ALK-ve for different risk groups (age, gender, histological subtype, the site of metastasis, and grade). Patients with adenocarcinoma showed better OSR than those with squamous cell carcinoma, $\mathrm{P}<0.07$. While other factors weren't significantly different. Conclusions: Patients with ALK gene rearrangement are resistant to chemotherapy, so they should be directed for individualized treatment, the prevalence of ALK+ve patients could be more than expected among the Egyptian population. further confirmation is required through multiple center population-based studies. Policymakers are invited for validating central laboratory, they are also recommended to enhance accessibility for diagnostic facilities and services, and adopting inhibitors of tyrosine kinase (TKI) as a new effective treatment strategy for NSCLC cases.

Keywords: ALK, NSCLC, FISH, TKI

Editor-in-Chief: Prof. M.L. Salem, Ph.D. - Article DOI: DOI: 10.21608/jcbr.2021.48701.1091
10 ARTICLE INFO

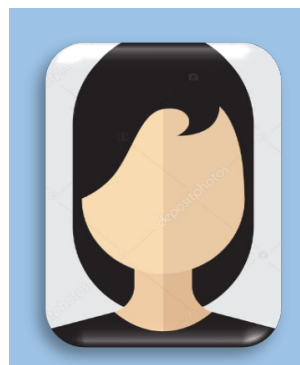

Article history

Received: November 8, 2020 Revised: May 21, 2021 Accepted: June 9, 2021

\section{Correspondence to:}

Marwa I. Abdelgawad, MD Clinical Oncology Department, Faculty of Medicine, Assiut University, Egypt Te.: 01004436476 Email: esmailmarwa@yahoo.com 


\section{INTRODUCTION}

Lung cancer and specifically the non-small cell subtype (NSCLC) is one of the main types of cancer-causing death among males and females, recent advances have enhanced our knowledge about lung cancer pathogenesis and management, altering survival rates, and prognosis of NSCLC.

Two acquired mutations in genes encoding tyrosine kinases on genetic and protein expression levels were detected and have highly therapeutic importance, they include Epidermal Growth Factor Receptor (EGFR), and Anaplastic lymphoma kinase (ALK), (Won et al., 2015) they can be used as a prognostic factor or potential biomarker. The rearrangement of fusion oncogene alters in vivo, and in vitro leading to a different clinicopathologic picture in about $5 \%$ of NSCLC patients (Baldi et al., 2014).

ALK receptor is a transmembrane protein that belongs to insulin-like tyrosine kinase receptor superfamilies, it's genetic code presents on ALK gene which is carried on the second chromosome, targeting these receptors by Small molecular tyrosine kinase inhibitors (TKIs) led to desirable progression-free survival (PFS), overall response rates (ORR), and enhanced the life of the patients compared to chemotherapy (Lin et al., 2019).

In anaplastic lymphoma, a fusion between ALK and Nucleophosmin (NPM1) occurs, leading to constitutive kinase activity, which will result in apoptosis inhibition and cell proliferation enhancement. It was reported that rearranged ALK gene is involved in the development of NSCLC, this is mediated by inversion of chromosome 2 and fusion between ALK and echinoderm microtubule-associated proteinlike 4(EML4) genes (Hida et al., 2017).

ALK-EML4 fusion in NSCLC patients was firstly defined in 2007. This genetic infusion is created by an inversion mutation of the short arm of the chromosome [Inv (2) (p21p23)], relocating the 3 '-end the kinase domain of ALK next to the 5 ' end of EML4, it was observed in vivo and in vitro that this inversion results in constitutive activation of ALK gene and oncogenic cell transformation (Fu et al., 2015).
There are several methods used for ALK gene analysis in cancer samples, they include fluorescence in situ hybridization (FISH) which is useful for detection of rearranged genes and reverse transcription polymerase chain reaction (RT-PCR) which is helpful to detect mutations in mRNA transcripts, and immunohistochemistry (IHC) which is used to detect overexpression of certain proteins.

It's important to select the proper method for ALK gene abnormalities in order to select appropriate patients for targeted treatments. It was reported in several studies, NSCLC patients respond to ALK tyrosine inhibitors such as Crizotinib, the response rate and 6-month free survival rate were $57 \%, 72 \%$, respectively (Sullivan and Planchard, 2016).

In spite of IHC is more cost-effective, and available in most diagnostic labs, FISH technique is considered the gold standard to detect rearranged ALK gene, using an ALK break-apart probe, regardless of the form of the translocation event (Ali et al., 2016).

Till now, few studies are reporting ALK gene mutation incidence among NSCLC Egyptian patients. We conducted this study to examine genetic mutations of ALK gene among Upper Egypt NSCLC patients undergoing treatment at our university, using FISH method. Then we correlated the clinical picture, and survival rates of patients with their genetic data.

\section{PATIENTS AND METHODS}

I-Patient and tissue selection: This research project was performed according to Good Clinical Practice (GCP) guidelines, the ethical guidelines included the declaration of Helsinki, and guiding principles of the Research advisory council (RAC) in X, and study approval was obtained from the Medical Ethics Committee. All patients have signed informed consent form to accept their enrollment and the analysis performed in the project. After enrollment, clinical data of all cases were collected.

This study was done in the Clinical Oncology Department, Clinical Pathology Department and Molecular Biology and Engineering Centre, X, during the period from December 2016 to March 2018. 
26 consecutive patients were enrolled and diagnosed as NSCLC (non-small lung carcinoma) by clinical, radiological, and histological examination.

\section{Eligibility Criteria}

- Ages Eligible for Study: 18 Years and older

- Sexes Eligible for Study: All

\section{Criteria}

\section{Inclusion Criteria}

- Eastern Cooperative Oncology Group (ECOG) performance status 0-2.

- Patients must have histologically or cytologically confirmed stage IV ALKpositive non-squamous non-small cell lung carcinoma (NSCLC). ALK rearrangement must have been demonstrated by a Food and Drug Administration (FDA) approved assay (Vysis fluorescence in situ hybridization [FISH] or Ventana immunohistochemistry [IHC]) or by nextgeneration sequencing (NGS).

- Patient must be willing and able to undergo a fresh biopsy or if the patient has a biopsy after progression on current tyrosinekinase inhibitor (TKI) within 3 months of study enrollment

- The patient must have study-specific informed consent

- Patients with asymptomatic treated or untreated brain metastases. Treated brain metastases are eligible as long as patients have measurable disease outside the brain according to RECIST 1.1. Anticonvulsants are allowed as long as the patient is neurologically stable and not deteriorating.

- Patients enrolled with asymptomatic brain metastases (mets) must have at least one measurable target extracranial lesion according to RECIST 1.1.

- Acute effects of any prior therapy resolved to baseline severity or to Common Terminology Criteria for Adverse Events (CTCAE) grade $=<1$ (except for alopecia, hearing loss)

- Not taking any medications.

- Women must not be pregnant or breastfeeding due to potential harm to the fetus or infant from ALK inhibitors if treated with them in the future.

\section{Exclusion Criteria}

- Patients with active malignancy other than ALK-positive non-squamous NSCLC within the last 2 years are excluded.

- Palliative RT (< 10 fractions) must have been completed at least 48 hours prior to study entry. Stereotactic or small field brain irradiation must have been completed at least 1 week prior to the study.

- History of interstitial lung disease or interstitial fibrosis, including a history of pneumonitis, obliterative bronchiolitis, pulmonary fibrosis. Patients with a history of prior radiation pneumonitis are not excluded.

- Active inflammatory gastrointestinal disease (such as Crohns, ulcerative colitis), chronic diarrhea, symptomatic diverticular disease, or any gastrointestinal disease.

- Clinically significant cardiovascular abnormalities.

- Active and clinically significant bacterial, fungal, or viral infection

- Patients with active or chronic pancreatitis based on lipase elevation, symptoms, and radiographic findings

- Other concomitant serious illness or organ system dysfunction.

Full history was taken from all patients, also clinical examination, computerized tomography, and chest radiology were done. Several laboratory tests were also carried out involving complete blood picture $(C B C)$, total and direct bilirubin, international normalized ratio, serum albumin, prothrombin time, alanine transaminase, bleeding time, aspartate transaminase, and bleeding time.

Information from medical records of all patients was extracted regarding age, gender, disease stage, and history of smoking, the histological features of the tumor, and outcomes of the therapy were also reviewed.

Tumor samples were obtained during surgery, which is the standard treatment approach used, these samples were collected and evaluated to check the availability of tumor tissue. Then, tissue biopsies underwent fixation in formalin, embedding in paraffin, and storage as formalinfixed, paraffin- embedded (FFPE) blocks. Before 
the beginning of assays, tissue staining with Hematoxylin and Eosin (H\&E), and analysis using a light microscope, for determination of the content and location of tumor cells inside the sample, were carried out.

II-ALK mutation analysis using FISH in ParaffinEmbedded Tissue Sections: ALK-rearranged gene was analyzed in $5-\mu \mathrm{m}$ unstained FFPE tissue samples obtained from lung biopsies using FISH technique. Firstly, tissue samples were put on a coated slide (such as Fisher Superfrost, cat. \# 12-550-15). Then, they were deparaffinized in xylene for 3 times, and for 10 minutes every time, dehydrated by washing for five minutes twice with $100 \%$ ethanol, and for five minutes twice with $96 \%$ ethanol, and later they were dried with air at room temperature. Incubation of tissue samples was done in salinesodium (SSC) for ten minutes at $75{ }^{\circ} \mathrm{C}$, then incubation for ten minutes at $37^{\circ} \mathrm{C}$ in $4 \mathrm{mg} / \mathrm{ml}$ pepsin (Sigma P-7012, in $0.9 \% \mathrm{NaCl} \mathrm{pH} \mathrm{1.5)} \mathrm{in}$ order to digest proteins.

Tissue samples were then washed in purified water, rinsed for 2 minutes in SSC twice at room temperature. Denaturation of the slides was done in $70 \%$ formamide, (twice) SSC for three to five minutes at $75{ }^{\circ} \mathrm{C}$. Tissue samples were quenched for two minutes in cold $70 \%$ ethanol $\left(2-8{ }^{\circ} \mathrm{C}\right)$. FISH assay was done according to the instructions of the manufacturer by a breakapart probe which is commercially available and designed to target specifically ALK gene in NSCLC patients (Vysis ALK Break Apart FISH probe Kit, Cytocell Aquarius “REF: LPS 019-SA"), ALK-rearranged genes were detected with a specific probe that's capable for hybridization to the $2 \mathrm{p} 23$ band on any part of the breakpoint of ALK gene. FISH technique includes utilizing labeled DNA probes, these probes are capable of binding and localizing certain sites in the genome insides cell nuclei o tumor samples. The Vysis break-apart FISH probe test has been used to target and detect ALK gene and partner genes such as EML4 (Ali et al., 2016).

Denaturation of the probe and hybridization solution $(10 \mu \mathrm{L})$ at $75{ }^{\circ} \mathrm{C}$ for five minutes was done, The Vysis LSI Cyclin D1, CEP11 was added to the slide for DNA denaturation in the tissue samples, and then coverslip was added and sealed. Overnight incubation of the slides in a humid chamber at $37{ }^{\circ} \mathrm{C}$ was done. Coverslips were removed gently after hybridization, and slide washing with 0.4 standard SSC $(\mathrm{pH} 7.0)$ in a Coplin jar for 2 minutes at $72^{\circ} \mathrm{C}$ was performed. Slides were transferred to another Coplin jar containing 0.1\% NP40/23 standard SSC solutions (pH7.0) for 1 minute. Counterstaining of nuclei was done using a mixture of Vectashieldantifade and $1000 \mathrm{mg} / \mathrm{ml}$ of 4-,6-diamidino-2-phenylindole dihydrochloride (Vector Laboratories, Inc., Burlingame, CA) at a ratio of 10:1. Coverslips were laid over the positions of hybridization.

III-Microscopy: Zeiss Axiovert 200 fluorescence microscope supplied with a high-resolution Leica CCD camera was used to detect clinicopathological characteristics of rearranged ALK gene, image processing was done using an imaging system and software (Leica, Germany).

IV-Interpretation: The LSI ALK 3'orange fluorescent-tagged DNA probe and The LSI ALK 5' green fluorescent-tagged DNA probe are capable of binding to neighboring matching DNA on ALK gene. Standard controls were used to conduct hybridization and assessment. At least 200 tumor cells without single signals or equivocal scoring were done.

In ALK-ve cells, there isn't chromosomal rearrangement, so the signals of the probe will appear as a single yellow signal or neighboring red and green signal, while in ALK +ve cells, there's the chromosomal rearrangement and the signals will be broken apart and appear as separate green and red signals. A single green or orange signal would be seen if there's a removed part of the gene. The quality of the slides and the number of green, yellow, and red signals were assessed and counted using a fluorescence microscope by skilled and trained medical professionals.

According to the scoring system proposed by Kwak et al, tumor cells with $15 \%$ or more (cut off value) separate green $5^{\prime}$ and red $3^{\prime}$ signals or isolated red $3^{\prime}$ signals with separated signal in $\geq$ 2 signal diameters, were considered positive for rearranged ALK gene, while cells with yellowish signals (overlapping red and green signals) were considered negative for ALK gene rearrangement (Peters et al., 2017). 


\section{Statistical analysis}

The characteristics of patients and tumor response were described using descriptive statistics. Kaplan-Meier survival analysis was used for estimation of progression-free Survival and Overall Survival (PFS and OS). The Cox regression model was used for Univariate analysis to analyze these parameters. Survival rates were analyzed by the log-rank test. Statistical significance was assumed when the $p$ value was less than 0.05 . Statistical analysis, data presentation and tables were made by JMP-SAS statistical software application (Version 9.4: SAS Institute, Cary, NC, USA).

\section{RESULTS}

The study objective estimates the clinicopathological and molecular characters in eligible lung cancer patients seen at tertiary hospitals in Upper Egypt (Assiut-Sohag-Elminia). Twenty-six cases of NSCLC were recruited in this study 21 of them were males. The enrolled patients had a median age of 60 years. The main presenting symptoms were breath shortness and cough $(n=19)$. Radiologically; the patients had right lung mass in 15 cases and were central in 17 patients. Other tumor characteristics and clinical (Table 1).

The primary pathological findings indicated most of the cases were given a diagnosis with adenocarcinoma, squamous cell carcinoma (14 ,6 cases, respectively), and the rest were given a diagnosis with undifferentiated carcinoma. The results of immunohistochemical analysis of TTF1 and CK5/6 molecules (Figure 1) classified the tumor into adenocarcinoma in 18 cases, and squamous cell carcinoma in 8 cases. The grading of the tumor was II in 11 cases, III in 10 cases and IV in 5 cases. FISH technique was capable of detecting the expression of ALK gene in 15 patients, while it wasn't detectable in the rest of the patients (Figure 1).

During data collection of the study, none of these parameters; tumor size, site, grade or stage showed significant association with ALK rearrangement (Table 2). The expression of ALK is frequently noticed in bronchial adenocarcinomas than squamous cell carcinoma $(p<0.002)$.
Patients who underwent investigation were followed up to 63 months, the mean $\pm S D$ was $20 \pm 11$ months, and the median was 18 months. The two-year survival rate for cases with NSLC, and the OSR were $68.8 \%, 51.6 \%$ respectively (Figure 3A). Patients with adenocarcinoma showed better OSR than those with squamous cell carcinoma (Figure 3B). While other factors weren't significantly different between ALK +ve patients and ALK -ve patients.

\section{DISCUSSION}

Egypt recorded one of the highest mortality rates of lung cancer similar to that of India. In 2014, based on the National Population-based Cancer Registry reports (2014), there will be an increase in lung cancer cases because of population growth and alteration of population structure. Lung cancer is the third most frequently observed type of cancer among Egyptian males specifically in Upper Egypt (2.08\%), it also affects $7.63 \%$ in Upper Egypt. Globally, Lung cancer is more frequent in males more than females with a ratio of 2.13:1. This data is confirmed in our study where 21 males versus 5 females were diagnosed with lung cancer. It was reported by WHO, that lung cancer is more frequent in males than women in less developed countries with a ratio of 2.38:1, and well-developed countries with a ratio 1.83:1 (Ibrahim et al., 2014; Ferlay et al., 2018).

ALK fusion prevalence, in early-stage and late stages of NSCLC, differs according to the ethnicity, and detection methodology. The deficiency of data registries in the Middle East leads to a lack of knowledge about ALK fusion mutation prevalence, so the calculation is estimated from international literature, it's reported to be about 5\% (Marchetti et al., 2016).

Our study with very small sample size demonstrated comparable results to the largest series studies measuring the prevalence of ALK predominance in European patients, which indicated that the prevalence of ALK +ve cases is $2.2 \%$ by FISH technique, and ALK IHC (any grade) $6.25 \%$ (Yun Ha et al., 2015). 

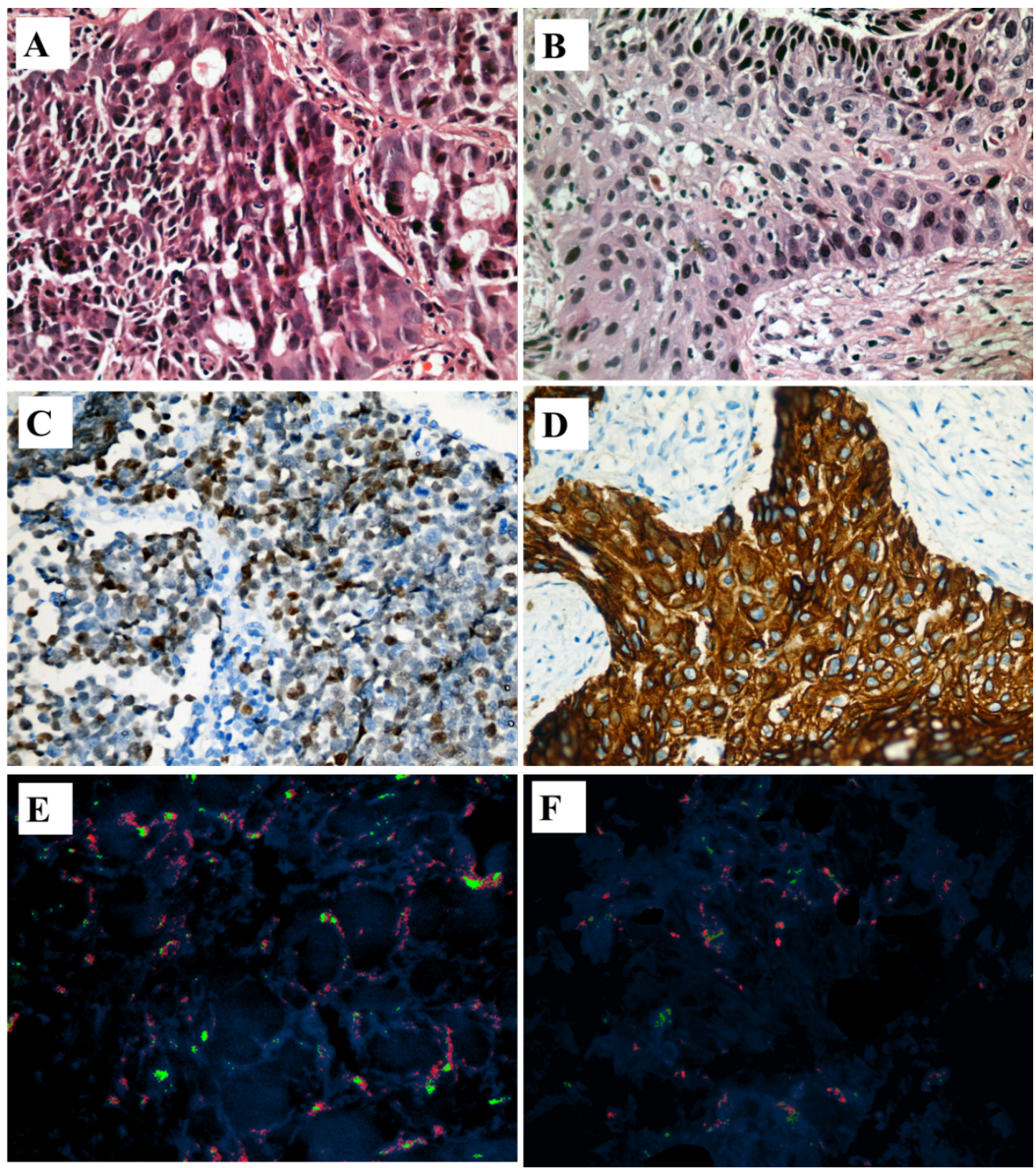

Figure 1. H\&E sections, immunostained sections and FISH section

Better identification of specific molecular markers with the advanced molecular techniques will aid in the prognostic and predictive values and also assists in the proper decision of therapy for different NSCLC subtypes. In USA, it's required to rely on techniques approved by FDA including FISH (e.g. Vysis Probes) or immunohistochemistry using Ventana ALK (D5F3) CDx assay for ALK positivity confirmation. While in European countries, immunohistochemistry is widely used for rearranged ALK gene assessment. More or less this is similar to our study, it is done through FISH. (Blackhall et al., 2014)
In 2014, The Japan Lung Cancer Society (JLCS) was concerned with the difficult situation of the diagnostic tools to be used to assure the security and efficiency of the chosen treatment administered in the trial. They are similar to those used for assessment in our study.(Mohar et al., 2016)

Usually, the ALK Mutations are detected from tumor tissue biopsy or cfDNA (cell-free DNA) liquid biopsy. There is a higher number of mutations in the ALK gene according to previous TKI treatment such as BRCA2 and TP53. 


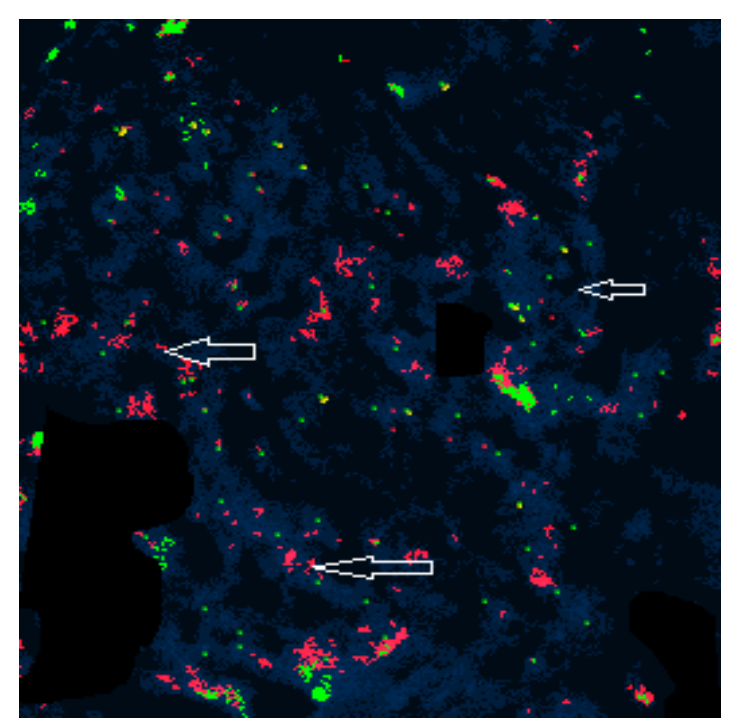

A (Positive)

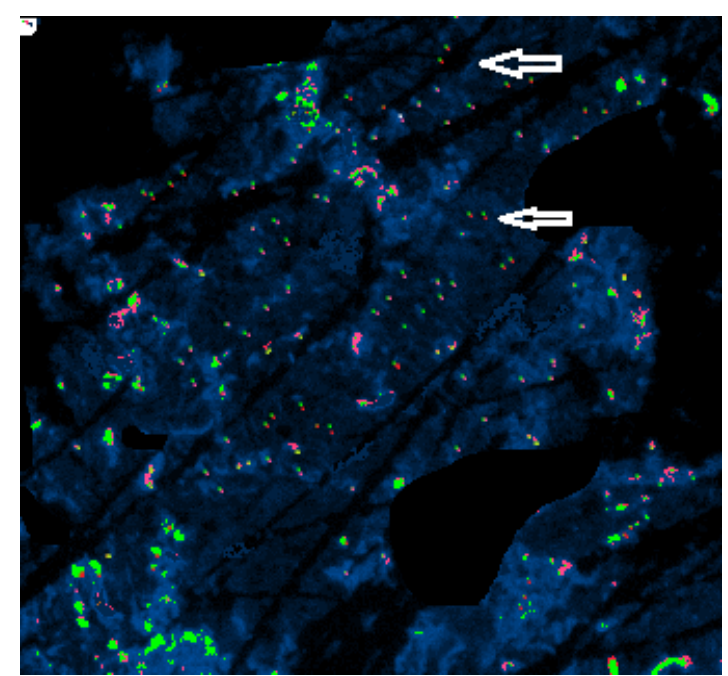

B) Negative

Figure 2.

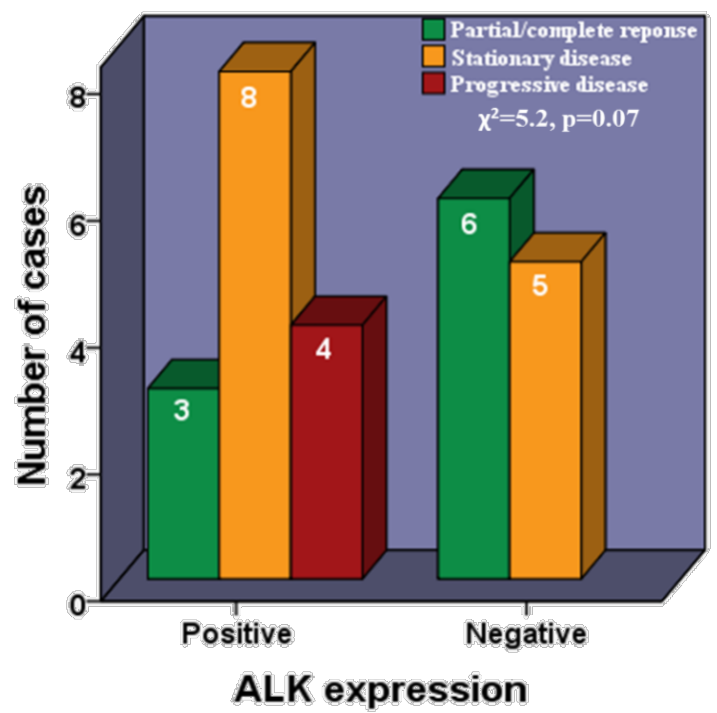

Figure 3. ALK expression is associated with stationary or progressive bronchial carcinoma
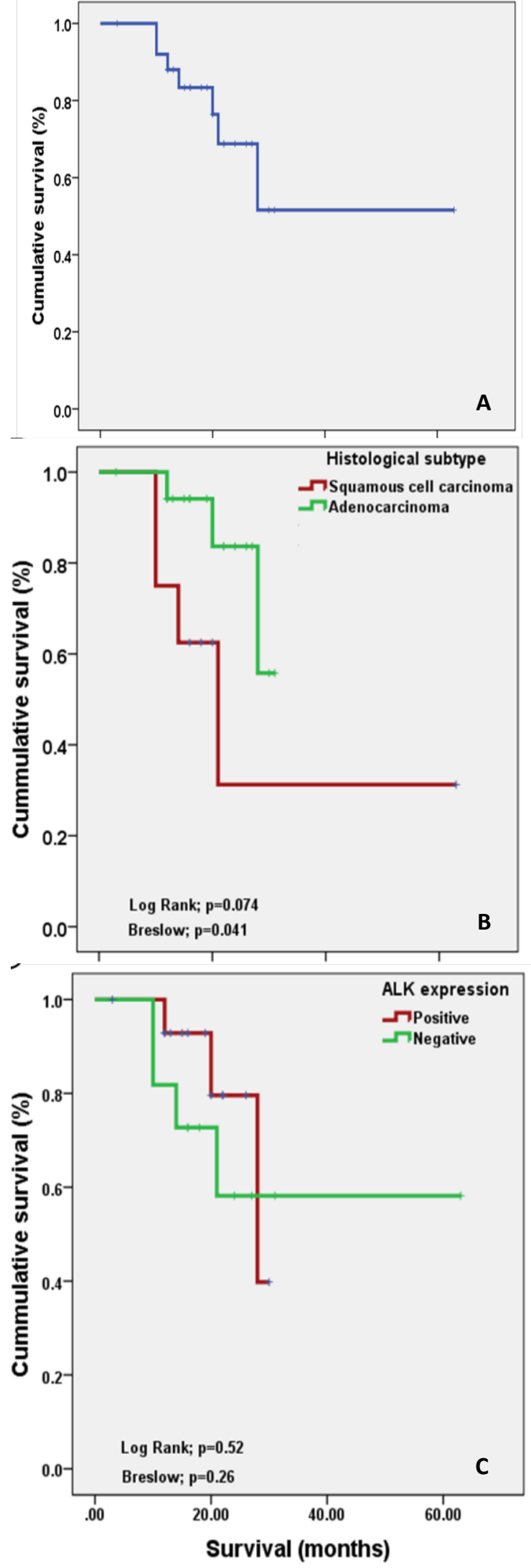

Figure 4. Kaplan-Meier graph for overall survival (A) and survival among different histological subtypes (B) and different ALK status 
Table 1. Clinical and tumor Characteristics

\begin{tabular}{|c|c|c|}
\hline \multicolumn{2}{|c|}{ Patients / Tumor characteristics } & $\begin{array}{c}\text { Patient number, } \\
\mathrm{N}=\mathbf{2 6}\end{array}$ \\
\hline \multicolumn{2}{|l|}{ Age range } & $43-80$ years \\
\hline \multicolumn{2}{|l|}{ Age mean $( \pm S D)$} & $61.88( \pm 10.40)$ \\
\hline \multicolumn{2}{|l|}{ Age median } & 60 years \\
\hline \multirow[t]{2}{*}{ Gender } & Males & 21 \\
\hline & Females & 5 \\
\hline \multicolumn{2}{|c|}{ cough and dyspnea } & 19 \\
\hline \multicolumn{2}{|l|}{ hemoptysis } & 6 \\
\hline \multicolumn{2}{|l|}{ bone pain } & 1 \\
\hline \multicolumn{2}{|l|}{ right lung mass } & 15 \\
\hline \multicolumn{2}{|l|}{ left lung mass } & 11 \\
\hline \multicolumn{2}{|l|}{ central masses } & 17 \\
\hline \multicolumn{2}{|c|}{ peripheral masses } & 9 \\
\hline \multicolumn{2}{|c|}{ bronchial obstruction } & 10 \\
\hline \multicolumn{2}{|l|}{ pleural effusion } & 8 \\
\hline \multicolumn{2}{|c|}{ chest wall infiltration } & 3 \\
\hline \multicolumn{2}{|c|}{ tumor size range } & $2.0-9.0 \mathrm{~cm}$ \\
\hline \multicolumn{2}{|c|}{ tumor size mean $( \pm S D)$} & $5.75( \pm 2.0)$ \\
\hline \multicolumn{2}{|c|}{ tumor size median } & $6.0 \mathrm{~cm}$ \\
\hline \multirow[t]{3}{*}{ tumor lesions } & T3 & 14 \\
\hline & T1 & 2 \\
\hline & $\mathrm{T} 4$ & 10 \\
\hline \multicolumn{2}{|c|}{$\begin{array}{l}\text { Absence of Hilar and mediastinal } \\
\text { lymphadenopathy }\end{array}$} & 7 \\
\hline \multicolumn{2}{|c|}{ N1 stage } & 6 \\
\hline \multicolumn{2}{|l|}{ N2 stage } & 12 \\
\hline \multicolumn{2}{|l|}{ N3 stage } & 1 \\
\hline \multirow{4}{*}{$\begin{array}{l}\text { Distant } \\
\text { metastasis (M1) } \\
\text { (10 cases) }\end{array}$} & liver & 1 \\
\hline & $\begin{array}{l}\text { suprarenal } \\
\text { glands }\end{array}$ & 2 \\
\hline & bone & 3 \\
\hline & brain & 4 \\
\hline
\end{tabular}

T: Tumor, N: Node, M: Metastases

In pre-existing germline mutations, somatic mutations of EGFR, ALK, ROS-1, RET, and BRAF will be affected and KRAS, C-MET may be changed. In the present study, no detection of these resistant genes as they are costly and still not fundamental for cases of resistant ALK inhibitors TKIs (Yang et al., 2014). ALK fusion detection in NSCLC patients indicates a specific group of NSCLCs patients with certain pathological and clinical characteristics. We encountered 11 ALK -ve patients confirmed by FISH method, Tumor cells with $15 \%$ or more separate green $5^{\prime}$ and red $3^{\prime}$ signals or isolated red $3^{\prime}$ signals with separated signal in $\geq 2$ signal diameters, were considered positive for rearranged ALK gene (Camidge et al., 2019).

PROFILE1014 trial (ASCO 2014) reported that the treatment with chemotherapy in addition to
TKI for ALK +ve patients had 10.9 median PFS, and $74 \%$ ORR, so it was more efficient than treatment with chemotherapy alone had 7.0 median PFS, AND 45\% ORR (Zhao et al., 2015).

Our results were different from those of PROFILE1007 phase III study in which TKI (Crizotinib) therapy lead to better PFS in comparison with chemotherapy (7.0 vs. 3.0 months, respectively), without overall survival positive outcomes due to increased crossover rates from the standard of care (pemetrexed or docetaxel) to Crizotinib arm in ALK +ve NSCLC patients. Few clinical trials reported that ALK+ patients tend to be adenocarcinoma harboring youth who are not smoking or smoking lightly (Pikor et al., 2013; Siegel, Miller and Jemal, 2019), these findings are different from our study as it is predominant in old patients with a median age of 60 years old.

The selection of patients is very important in molecular-targeted treatment. Positive alterations tend to be higher among patients with the specific clinical picture and pathological characteristics such as male gender, non-smokers, and youth. Also, EML4ALK tumors tend to be adenocarcinoma with certain histological characteristics (Takahashi et al., 2010). These results are similar to that of our study.

As stated by Ning-Ning et al. 2014, rearranged ALK gene is more frequent in poorly differentiated tumor in the population of the study. Notably, Takahashi et al. reported that rearranged ALK gene is detected in 5 ALK +ve patients with poorly differentiated tumor. (Takahashi et al., 2010; Siegel, Miller and Jemal, 2019) This is different from our study as it is predominant in moderately differentiated grading and may be due to somewhat different eligibility criteria as age, sex, histopathology and stage.

More than half of the cases in this study revealed positivity to ALK and rearranged ALK gene presented in one-third of patients in Ning et al. study (Rekhtman et al., 2013), which was higher than reported ranges. Most of these patients in the two studies shared some of the clinicopathological features and thereby might affect the positive detection frequency. 
Table 2. Relation between clinic-radiological and pathological parameters with ALK expression

\begin{tabular}{|c|c|c|c|c|}
\hline \multirow{2}{*}{\multicolumn{2}{|c|}{ Parameter }} & \multicolumn{2}{|c|}{ ALK rearrangement } & \multirow{3}{*}{$\frac{\text { P value }}{0.83}$} \\
\hline & & \multirow{2}{*}{$\begin{array}{c}\text { Positive } \\
\begin{array}{c}5.8(1.8) \\
6\end{array}\end{array}$} & \multirow{2}{*}{$\begin{array}{c}\text { Negative } \\
5.7(2.3) \\
5\end{array}$} & \\
\hline Tumor size $(\mathrm{cm})$ & $\begin{array}{l}\text { Mean (SD) } \\
\text { Median }\end{array}$ & & & \\
\hline Tumor site (n) & $\begin{array}{l}\text { Central } \\
\text { Peripheral }\end{array}$ & $\begin{array}{c}11 \\
4\end{array}$ & $\begin{array}{l}6 \\
5\end{array}$ & 0.32 \\
\hline Histological type (n) & $\begin{array}{l}\text { Adenocarcinoma } \\
\text { Squamous cell carcinoma }\end{array}$ & $\begin{array}{c}14 \\
1\end{array}$ & $\begin{array}{l}4 \\
7\end{array}$ & 0.002 \\
\hline Tumor grade $(\mathrm{n})$ & $\begin{array}{l}\text { II } \\
\text { III } \\
\text { IV }\end{array}$ & $\begin{array}{l}8 \\
4 \\
3\end{array}$ & $\begin{array}{l}3 \\
6 \\
2\end{array}$ & 0.32 \\
\hline Pleural effusion (n) & $\begin{array}{l}\text { Absent } \\
\text { Present }\end{array}$ & $\begin{array}{c}11 \\
4\end{array}$ & $\begin{array}{l}7 \\
4\end{array}$ & 0.59 \\
\hline T stage $(n)$ & $\begin{array}{l}\text { T1 } \\
\text { T3 } \\
\text { T4 }\end{array}$ & $\begin{array}{l}1 \\
8 \\
6\end{array}$ & $\begin{array}{l}1 \\
6 \\
4\end{array}$ & 0.96 \\
\hline$N$ stage $(n)$ & $\begin{array}{l}\text { N0/N1 } \\
\text { N2/N3 }\end{array}$ & $\begin{array}{l}6 \\
9\end{array}$ & $\begin{array}{l}7 \\
4\end{array}$ & 0.23 \\
\hline M stage (n) & $\begin{array}{l}\text { M0 } \\
\text { M1 }\end{array}$ & $\begin{array}{c}11 \\
4\end{array}$ & $\begin{array}{l}5 \\
6\end{array}$ & 0.15 \\
\hline
\end{tabular}

T: Tumor, N: Node, M: Metastases

This difference from the reported well-known incidence of ALK positivity may be due to different sample sizes and the recruitment of patients.

In Crizotinib studies, FISH technique was used for +ve patients' detection, this is similar to our study which depends on FISH only for ALK detection. Fortunately, and unfortunately, in Crizotinib studies, double-positive using FISH and IHC patients were noted to have a higher response rate. These results recommend that there could be false-positive and negative patients detected by FISH. Recent publications recommend that FISH analysis should be carried out for IHC positive patients, while others recommend that patients who were validated carefully by IHC could be screened to be analyzed by FISH; qRT-PCR wasn't recommended to substitute FISH technique (Rekhtman et al., 2013).

Ning et al; predicated that patient with moderate of strong expression of ALK gene has better OS2, and reduced death risk, these predictions were done using univariate analysis due to small sample size (Zhang et al., 2014). These predictions are similar to our findings which indicated improved overall survival rates among patients with moderate or strong expression of ALK gene, these results were obtained from Kaplan-Meier survival curves.
But in this trial, the expression of ALK gene was positively associated with improved survival rates, these findings are in contrast to ours.

\section{CONCLUSIONS AND RECOMMENDATIONS}

In this study, the clinical benefits of TKI therapy, which are oral ALK-targeted inhibitors with low toxicity, for advanced NSCLC patients were emphasized, this achieved a remarkable step in individualized medicine and interpretation of genome-wide mutation analysis in developed countries.

An organized Screening strategy of Anaplastic Lymphoma Kinase in Egypt specifically in Upper Egypt with Immunohistochemistry or $\mathrm{H}$-score PCR should be applied directly whenever a case is diagnosed with NSCLC either in early or advanced stages as there is no prospective data describes the prognostic significance of ALK+ve results.

It is worthy to know that the sensitivity and affordability of IHC and QRT-PCR, ALK test based on IHC is considered a cost-effective method to screen for cases who may get an advantage of treatment with ALKIs, then FISH or PCR could be used for confirmation if required.

Small randomized- clinical trials are required for assessment of ALK gene alterations status before intended treatment of ALK inhibitors (which are expensive in developing countries) to 
overcome the problem of resistance development especially central nervous system (CNS) relapse.

\section{ABBREVIATIONS}

- ALK; Anaplastic Lymphoma Kinase

- NSCLC: Non-Small Cell Lung Cancer

- IHC: Immunohistochemistry

- FISH: Fluorescent In-situ Hybridization

- TKI: Tyrosine Kinase Inhibitors

- EGFR: Epidermal Growth Factor Receptors

\section{CONFLICTS OF INTEREST}

All authors have approved this article and declare no conflicts of interest.

\section{FUND}

No fund was received for this work.

\section{REFERENCES}

Ali SM, Hensing T, Schrock AB (2016). Comprehensive Genomic Profiling Identifies a Subset of Crizotinib-Responsive ALK Rearranged Non-Small Cell Lung Cancer Not Detected by Fluorescence In Situ Hybridization. The Oncologist, 21(6):762-770.

Baldi L, Mengoli MC, Bisagni A, Banzi MC, Boni C, Rossi G (2014). Concomitant EGFR mutation and ALK rearrangement in lung adenocarcinoma is more frequent than expected: Report of a case and review of the literature with demonstration of genes alteration into the same tumor cells. Lung Cancer, 86(2):291-295.

Blackhall FH, Peters S, Bubendorf L (2014). Prevalence and clinical outcomes for patients with ALK-positive resected stage I to III adenocarcinoma: Results from the European Thoracic Oncology Platform Lungscape project. Journal of Clinical Oncology, 32(25):2780-2787.

Camidge DR, Dziadziuszko R, Peters S (2019). Updated Efficacy and Safety Data and Impact of the EML4-ALK Fusion Variant on the Efficacy of Alectinib in Untreated ALK-Positive Advanced Non-Small Cell Lung Cancer in the Global Phase III ALEX Study. Journal of Thoracic Oncology, 14(7):1233-1243.

Ferlay J, Soerjomataram I, Ervik M, Dikshit R, Eser S, Mathers C, Rebelo M, Parkin DM, Forman D BF (2012). GLOBOCAN 2012: Estimated Cancer Incidence, Mortality and Prevalence Worldwide in v1.0. IARC Cancer Base No 11. 2018; ISBN-13 D.

Fu S, Wang HY, Wang F (2015). Clinicopathologic characteristics and therapeutic responses of chinese patients with non-small cell lung cancer who harbor an anaplastic lymphoma kinase rearrangement. Chinese Journal of Cancer, 34(9): 1-9.

Hida T, Nokihara H, Kondo M (2017). Alectinib versus crizotinib in patients with ALK-positive nonsmall-cell lung cancer (J-ALEX): an open-label, randomised phase 3 trial. The Lancet. 390(10089):29-39.

Ibrahim AS, Khaled HM, Mikhail NN, Baraka H, Kamel $H$ (2014). Cancer incidence in Egypt: Results of the national population-based cancer registry program. Journal of Cancer Epidemiology, 2014 (ID 437971): 18. Hindawi Publishing Corporation, 2014.

Lin C, Shi X, Yang S (2019). Comparison of ALK detection by FISH, IHC and NGS to predict benefit from crizotinib in advanced non-smallcell lung cancer. Lung Cancer, 131(October):6268. doi:10.1016/j.lungcan.2019.03.018.

Marchetti A, Di Lorito A, Pace MV (2016). ALK protein analysis by IHC staining after recent regulatory changes: A comparison of two widely used approaches, revision of the literature, and a new testing algorithm. Journal of Thoracic Oncology, 11(4):487-495.

Mohar B, Smojver Ježek S, Rajković Molek K (2016). Detection of an EGFR mutation in cytological specimens of lung adenocarcinoma. Cytopathology. John Wiley \& Sons, Ltd (10.1111), 27(6):444-451.

Peters S, Camidge DR, Shaw AT (2017). Alectinib versus Crizotinib in Untreated ALK -Positive Non-Small-Cell Lung Cancer. New England Journal of Medicine, 377(9):829-838.

Pikor LA, Ramnarine VR, Lam S, Lam WL (2013). Genetic alterations defining NSCLC subtypes and their therapeutic implications. Lung Cancer. 82(2):179-189.

Rekhtman N, Ang DC, Riely GJ, Ladanyi M, Moreira AL (2013). KRAS mutations are associated with solid growth pattern and tumor-infiltrating leukocytes in lung adenocarcinoma. Modern Pathoogy, 26910):1307-1319.

Siegel RL, Miller KD, Jemal A. Cancer statistics, (2019). CA: Cancer Journal for Clinicians, 69(1):7-34.

Sullivan I, Planchard D (2016). ALK inhibitors in nonsmall cell lung cancer: The latest evidence and developments, Therapeutic Advances in Medical Oncology, 8(1):32-47.

Takahashi T, Sonobe M, Kobayashi M, et al (2010). Clinicopathologic features of non-small-cell lung cancer with EML4-ALK fusion gene. Annals of Surgical Oncology, 17(3):889-897.

Won JK, Keam B, Koh J (2015). Concomitant ALK translocation and EGFR mutation in lung 
cancer: A comparison of direct sequencing and sensitive assays and the impact on responsiveness to tyrosine kinase inhibitor. Annals of Oncology, 26(2): 348-354.

Yang JJ, Zhang XC, Su J (2014). Lung cancers with concomitant egfr mutations and ALK rearrangements: Diverse responses to EGFRTKI and crizotinib in relation to diverse receptors phosphorylation. Clinical Cancer Research, 20(5):1383-1392.

Yun Ha S, Choi S-J, Ho Cho J (2015). Lung cancer in never-smoker Asian females is driven by oncogenic mutations, most often involving EGFR. Oncotarge, 6(7):5465-5474.
Zhang NN, Liu YT, Ma L (2014). The molecular detection and clinical significance of ALK rearrangement in selected advanced non-small cell lung cancer: ALK expression provides insights into ALK targeted therapy. PLoS One, 9(1): 84501.

Zhao F, Xu M, Lei H (2015). Clinicopathological characteristics of patients with non-small-cell lung cancer who harbor EML4-ALK fusion gene: A meta-analysis. PLoS One, 10(2):1-13. 